Supplement of

\title{
Chemical composition and hydrolysis of organic nitrate aerosol formed from hydroxyl and nitrate radical oxidation of $\alpha$-pinene and $\beta$-pinene
}

Masayuki Takeuchi and Nga L. Ng

Correspondence to: Nga L. Ng (ng@chbe.gatech.edu)

The copyright of individual parts of the supplement might differ from the CC BY 4.0 License. 


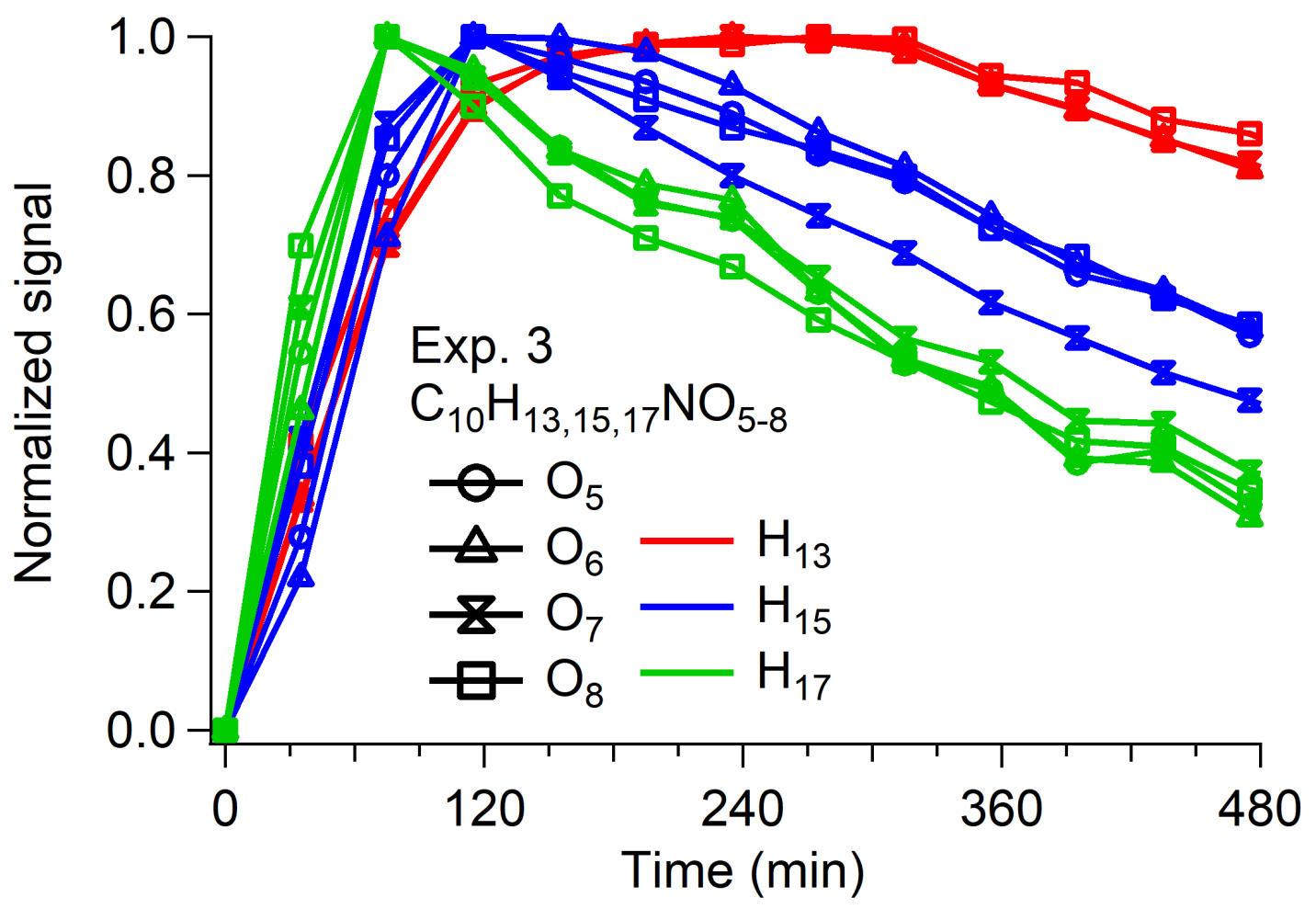

17 Figure S1. FIGAERO-HR-ToF-I-CIMS time-series data of select organic nitrate aerosol. All combinations 18 of $\mathrm{C}_{10} \mathrm{H}_{13,15,17} \mathrm{NO}_{5-8}$ with different oxygen and nitrogen numbers are shown here. Different symbols 19 correspond to compounds with different oxygen numbers, while different colors correspond to compounds 20 with different nitrogen numbers. Shown are the data from Exp. $3(\alpha$-pinene+OH$\cdot)$, though very similar 21 trends are observed for $\beta$-pinene $+\mathrm{OH} \cdot$ from Exp. 6. 


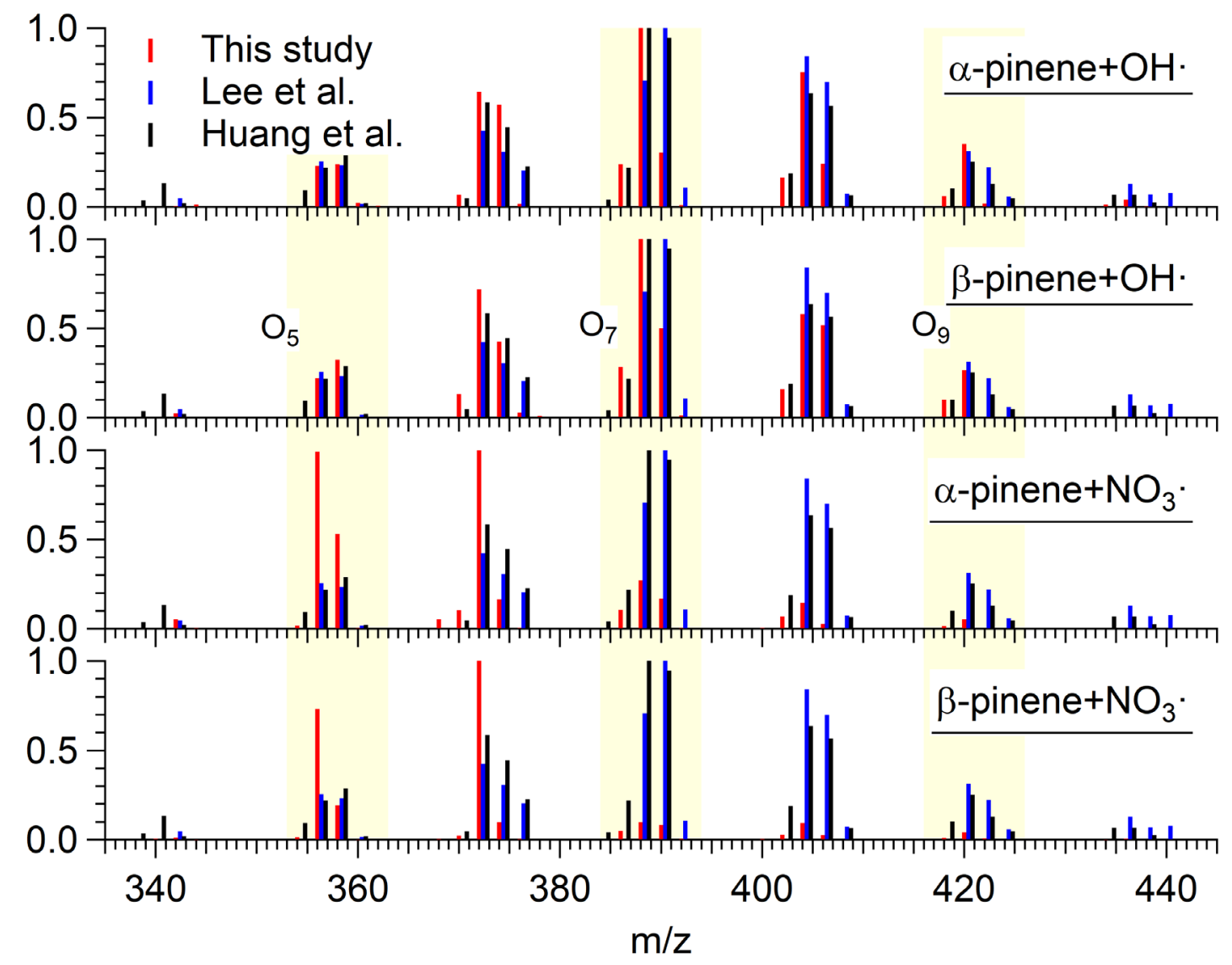

24 Figure S2. Comparison of FIGAERO-HR-ToF-I-CIMS mass spectra of organic nitrate aerosols (i.e., $25 \mathrm{C}_{10} \mathrm{H}_{11,13,15,17,19,21} \mathrm{NO}_{4-11}$ ) with ambient measurement data (Lee et al., 2016; Huang et al., 2019). All mass 26 spectra are normalized to the maximum signal. 


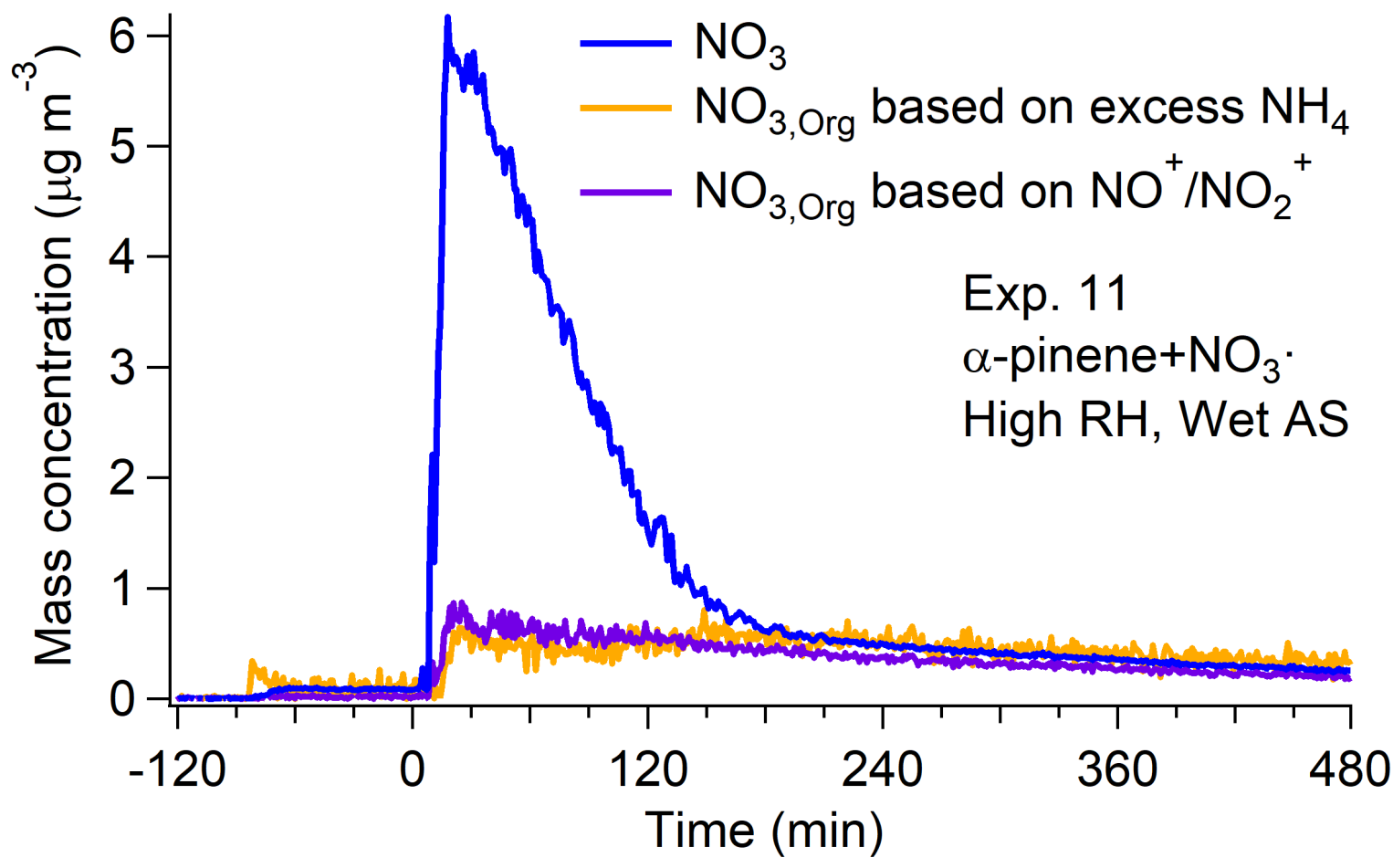

Figure S3. Concentrations of $\mathrm{NO}_{3}$ and $\mathrm{NO}_{3}$, Org derived from two independent methods. "Excess $\mathrm{NH}_{4}$ " refers

31 to a method to apportion the inorganic nitrate contribution to $\mathrm{NO}_{3}$ based on the increase in $\mathrm{NH}_{4}$ and 32 "NO ${ }^{+} / \mathrm{NO}_{2}{ }^{+"} "$ refers to the method based on its ratio (Farmer et al., 2010). 

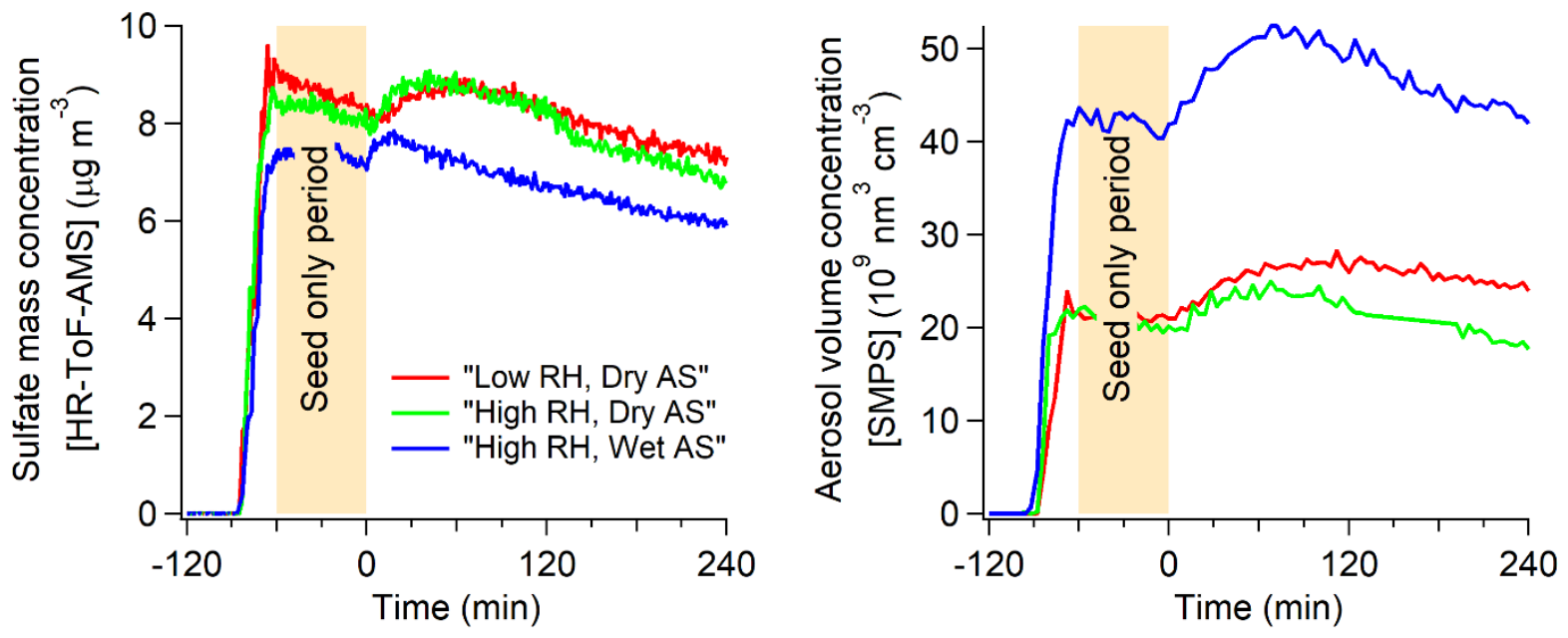

34 Figure S4. HR-ToF-AMS time-series data of $\mathrm{SO}_{4}$ and SMPS aerosol volume concentration in Exp. 3 (low 35 RH, dry AS), Exp. 4 (high RH, dry AS), and Exp. 5 (high RH, wet AS). A significant difference in the 36 volume concentration among the experiments indicates the deliquesced nature in Exp. 5 (high RH, wet AS) 37 and the effloresced nature of seed particles in Exp. 4 (high RH, dry AS). 


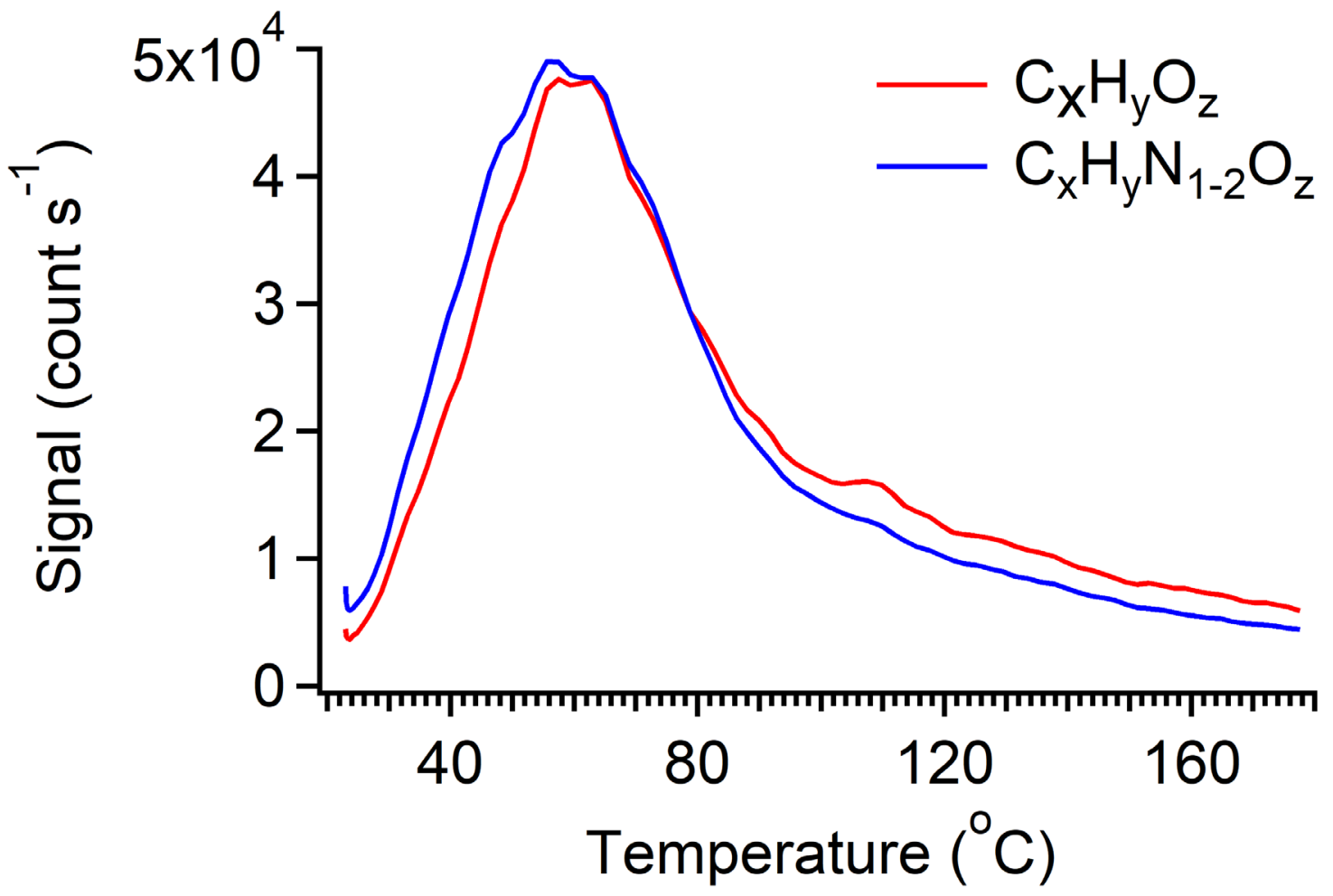

Figure S5. Thermal desorption profiles of $\mathrm{C}_{x} \mathrm{H}_{y} \mathrm{O}_{z}$ and $\mathrm{C}_{x} \mathrm{H}_{y} \mathrm{~N}_{1-2} \mathrm{O}_{z}$ in FIGAERO-HR-ToF-I-CIMS from

41 Exp. 3. Data points are averages of three desorption cycles around the peak SOA growth.

42

43 


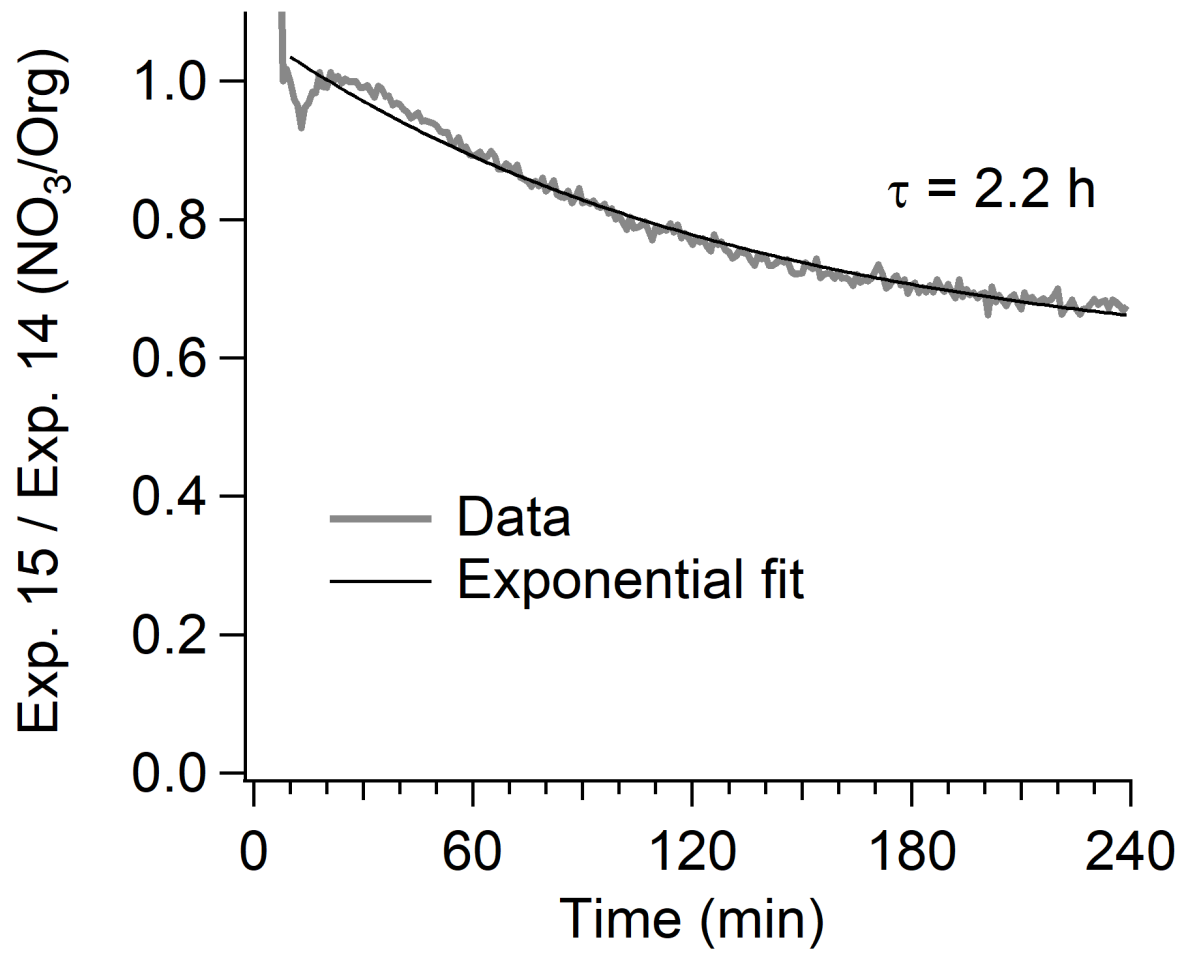

45 Figure S6. Time-series data of $\mathrm{NO}_{3} / \mathrm{Org}$ in Exp. 15 normalized to that in Exp. 14 based on the method 46 present in prior study (Boyd et al., 2015).

47 


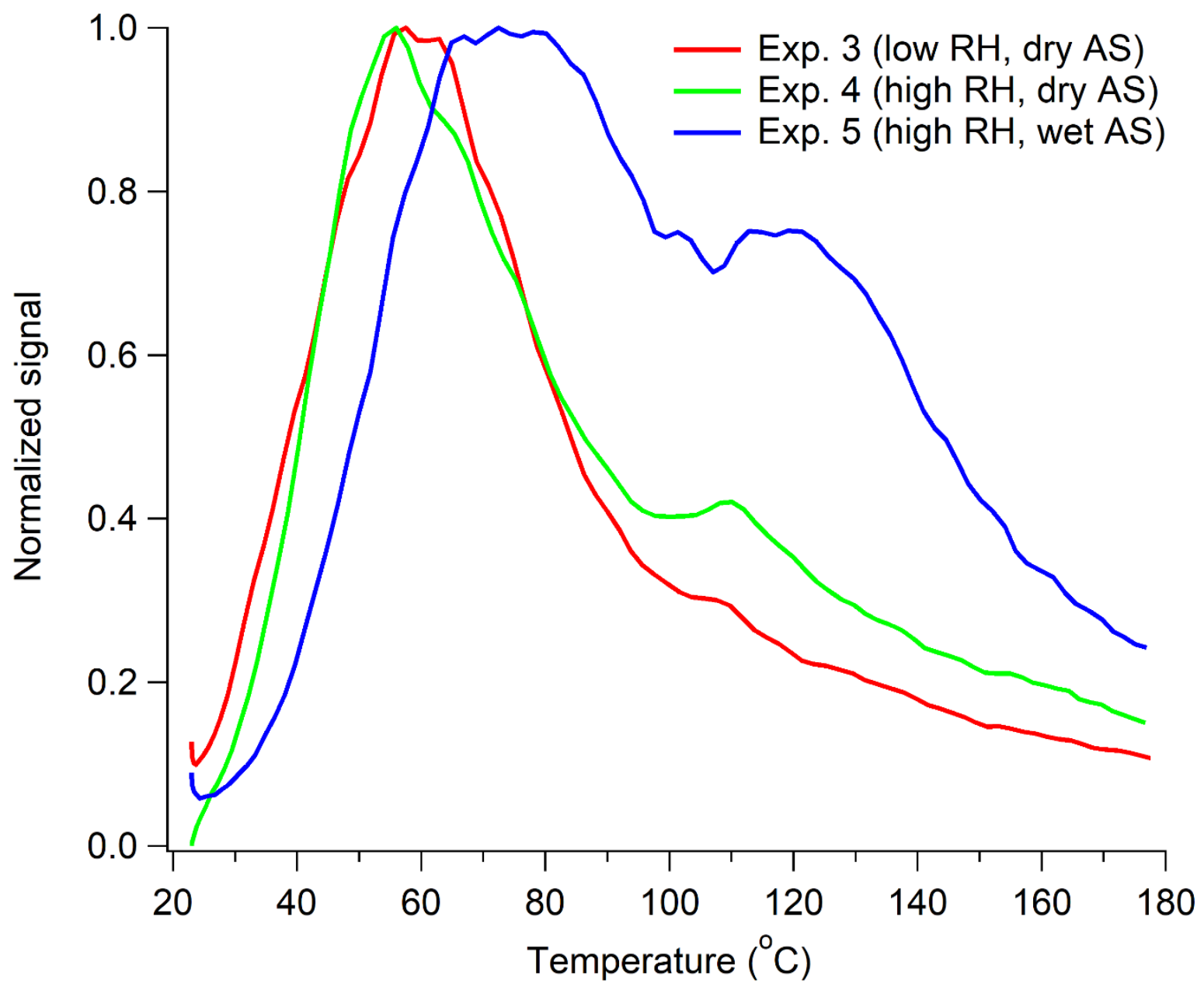

49 Figure S7. Average thermogram of organic aerosol (i.e., organic nitrate and non-nitrated organic aerosol)

50 at the peak of SOA growth in Exp. 3-5. Signals are normalized to the maximum signal for each experiment. 
51 Table $\mathrm{S} 1$. Summary of $\mathrm{R}_{\mathrm{AN}}$ and $\mathrm{R}_{\mathrm{ON}}$ applied to derive the concentration of $\mathrm{NO}_{3, \mathrm{Org}}$. $\mathrm{R}_{\mathrm{AN}}$ from $300 \mathrm{~nm}$ 52 ammonium nitrate particle at the nearest date is used unless noted otherwise. $\mathrm{R}_{\mathrm{ON}} / \mathrm{R}_{\mathrm{AN}}$ used for high $\mathrm{RH}$ 53 experiments are taken from the same experiment but under low RH experiments.

\begin{tabular}{|c|c|c|c|}
\hline ID & $\mathrm{R}_{\mathrm{AN}}$ & $\mathrm{R}_{\mathrm{ON}}$ & $\mathrm{R}_{\mathrm{ON}} / \mathrm{R}_{\mathrm{AN}}$ \\
\hline 1 & 2.87 & 6.25 & 2.18 \\
\hline 2 & 2.87 & 6.25 & 2.18 \\
\hline 3 & 2.80 & 5.75 & 2.05 \\
\hline 4 & 2.80 & 5.75 & 2.05 \\
\hline 5 & 2.88 & 5.91 & 2.05 \\
\hline 6 & 3.06 & 5.02 & 1.64 \\
\hline 7 & 3.06 & 5.02 & 1.64 \\
\hline 8 & 3.24 & 8.64 & 2.67 \\
\hline 9 & 2.87 & 7.66 & 2.67 \\
\hline 10 & 2.70 & 8.24 & 3.05 \\
\hline 11 & 2.80 & 8.55 & 3.05 \\
\hline 12 & 2.80 & 8.60 & 3.07 \\
\hline 13 & 2.88 & 8.85 & 3.07 \\
\hline 14 & 2.87 & 7.13 & 2.48 \\
\hline 15 & $2.56^{\mathrm{a}}$ & 6.36 & 2.48 \\
\hline
\end{tabular}

$54 \overline{{ }^{a}} \mathrm{R}_{\mathrm{AN}}$ is taken from 30-min average of $\mathrm{NO}^{+} / \mathrm{NO}_{2}{ }^{+}$during seed only period as the $\mathrm{R}_{\mathrm{AN}}$ from the calibration at 55 the nearest date is slightly higher.

56

57 
58 Table S2. Fraction of ${ }_{\mathrm{p}} \mathrm{ON}$ based on the number of carbon in each system.

\begin{tabular}{ccccc}
\hline System & $\mathrm{C}_{\leq 9} \mathrm{pON}$ & $\mathrm{C}_{10 \mathrm{p}} \mathrm{ON}$ & $\mathrm{C}_{11-19 \mathrm{p}} \mathrm{ON}$ & $\mathrm{C}_{20 \mathrm{p}} \mathrm{ON}$ \\
\hline$\alpha$-pinene+ $+\mathrm{OH} \cdot$ & $47 \%$ & $52 \%$ & $1 \%$ & $0 \%$ \\
$\beta$-pinene $+\mathrm{OH} \cdot$ & $58 \%$ & $41 \%$ & $1 \%$ & $0 \%$ \\
$\alpha$-pinene $+\mathrm{NO}_{3}$. & $11 \%$ & $26 \%$ & $8 \%$ & $54 \%$ \\
$\beta$-pinene $+\mathrm{NO}_{3}$. & $10 \%$ & $58 \%$ & $4 \%$ & $28 \%$ \\
\hline
\end{tabular}

59 
Boyd, C. M., Sanchez, J., Xu, L., Eugene, A. J., Nah, T., Tuet, W. Y., Guzman, M. I., and Ng, N. L.: 63 Secondary organic aerosol formation from the beta-pinene+NO3 system: effect of humidity and peroxy radical fate, Atmos Chem Phys, 15, 7497-7522, 10.5194/acp-15-7497-2015, 2015.

65 Farmer, D. K., Matsunaga, A., Docherty, K. S., Surratt, J. D., Seinfeld, J. H., Ziemann, P. J., and Jimenez, 66 J. L.: Response of an aerosol mass spectrometer to organonitrates and organosulfates and implications for 67 atmospheric chemistry, P Natl Acad Sci USA, 107, 6670-6675, 10.1073/pnas.0912340107, 2010.

68 Huang, W., Saathoff, H., Shen, X. L., Ramisetty, R., Leisner, T., and Mohr, C.: Chemical Characterization 69 of Highly Functionalized Organonitrates Contributing to Night-Time Organic Aerosol Mass Loadings and 70 Particle Growth, Environ Sci Technol, 53, 1165-1174, 10.1021/acs.est.8b05826, 2019.

71 Lee, B. H., Mohr, C., Lopez-Hilfiker, F. D., Lutz, A., Hallquist, M., Lee, L., Romer, P., Cohen, R. C., Iyer, 72 S., Kurten, T., Hu, W. W., Day, D. A., Campuzano-Jost, P., Jimenez, J. L., Xu, L., Ng, N. L., Guo, H. Y., 73 Weber, R. J., Wild, R. J., Brown, S. S., Koss, A., de Gouw, J., Olson, K., Goldstein, A. H., Seco, R., Kim, 74 S., McAvey, K., Shepson, P. B., Starn, T., Baumann, K., Edgerton, E. S., Liu, J. M., Shilling, J. E., Miller, 75 D. O., Brune, W., Schobesberger, S., D'Ambro, E. L., and Thornton, J. A.: Highly functionalized organic 76 nitrates in the southeast United States: Contribution to secondary organic aerosol and reactive nitrogen 77 budgets, P Natl Acad Sci USA, 113, 1516-1521, 10.1073/pnas.1508108113, 2016. 